\title{
Feasibility study of a mini fuel cell to detect interference from a cellular phone
}

\author{
M.O. Abdullah*, Y.K. Gan \\ Mechanical and Manufacturing System Engineering, Faculty of Engineering, Universiti Malaysia Sarawak, \\ 94300 Kota Samarahan, Sarawak, Malaysia \\ Received 14 April 2005; accepted 9 May 2005 \\ Available online 11 July 2005
}

\begin{abstract}
Fuel cells produce electricity without involving combustion processes. They generate no noise, vibration or air pollution and are therefore suitable for use in many vibration-free power-generating applications. In this study, a mini alkaline fuel cell signal detector system has been designed, constructed and tested. The initial results have shown the applicability of such system for used as an indicator of signal disturbance from cellular phones. A small disturbance even at $4 \mathrm{mV} \mathrm{cm}^{-1}$, corresponding to an amplitude of 12-18 $\mathrm{mG}$ in terms of electromagnetic field, can be well detected by such a device. Subsequently, a thermodynamics model has been developed to provide a parametric study by simulation to show the likely performance of the fuel cell alone in other environments. As such the model can provide many useful generic design data for alkaline fuel cells. Two general conclusions can be drawn from the present theoretical study: (i) fuel cell performance increases with temperature, pressure and correction factor, $C_{\mathrm{f}}$; (ii) the temperature factor $(E / T)$ increases with increasing temperature and with increasing pressure factor.
\end{abstract}

(C) 2005 Elsevier B.V. All rights reserved.

Keywords: Signal detector; Alkaline fuel cell; Signal disturbance; Environmental health; Cellular phone

\section{Introduction}

A fuel cell is an electrochemical device that produces electricity via inverse electrolysis. A chemical reaction and electrical charge transfer occurs within the fuel cell. This is very similar to the way a battery produces electricity. Unlike a battery, a fuel cell produces electricity as long as there is a continuous supply of fuel. No combustion however, nor noise generation takes place in the fuel cell.

The aforesaid advantages have encouraged the application of fuel cells in the signal sensing applications. For instance, Kim et al. [1] used a polymer electrolyte membrane (PEM) fuel cell for the detection of ethanol gas concentration. A two-electrode sensor cell for CO detection in a hydrogenrich gas had been investigated by Planje et al. [2]. Fuel cell sensors for breath testing and environmental monitoring by

\footnotetext{
* Corresponding author. Tel.: +60 82 679301; fax: +60 82672317.

E-mail address: amomar@feng.unimas.my (M.O. Abdullah).
}

gas discrimination have been investigated by Bull et al. [3]. These efforts have encouraged the present application for signal detection in cellular phones.

With the growing interest in fuel cells, the alkaline fuel cell (AFC) is said to be one of the most promising candidates [4]. The long lifetime and the possibility to use non-noble catalysts [4-6] give it advantages over other types of fuel cell system. It is considered that the kinetics of oxygen reduction is superior in an alkaline solution than in acid, which allows the use of less expensive catalysts to obtain an equivalent reaction rate $[3,7]$. Also, compared with other fuel cells, the reaction in the AFC occurs at a relatively low temperature.

The number of anecdotal reports of symptoms experienced by hand-phone users due to electromagnetic effects and the low-level radio frequency fields around the world is increasing [8-10]. These symptoms include headaches, dizziness, warmth or tingling around the ear and face, and difficulties in concentrating, see Chia et al. [8]. It is believed 